\title{
Seroprevalence and distribution of serogroup-specific pathogenic Leptospira antibodies in cattle and buffaloes in the state of Andhra Pradesh, India
}

\author{
Anusha Alamuri ${ }^{1,2}$, Sushma R. A. Thirumalesh ${ }^{1,2}$, S. Sowjanya Kumari ${ }^{1,2}$, K. Vinod Kumar $^{1}$, Parimal Roy ${ }^{1}$ \\ and V. Balamurugan ${ }^{1}$
}

\begin{abstract}
1. Indian Council of Agricultural Research-National Institute of Veterinary Epidemiology and Disease Informatics, Yelahanka, Bengaluru, Karnataka, India; 2. Department of Microbiology, Jain University, Bengaluru, Karnataka, India. Corresponding author: V. Balamurugan, e-mail: b.vinayagamurthy@icar.gov.in

Co-authors: AA: venkat.anu125@gmail.com, SRAT: assadi.sushma@gmail.com, SSK: sowjanyas817@gmail.com, KVK: vinodkmr33@gmail.com, PR: parimalroy580@gmail.com
\end{abstract}

Received: 11-04-2019, Accepted: 02-07-2019, Published online: 08-08-2019

doi: 10.14202/vetworld.2019.1212-1217 How to cite this article: Alamuri A, Thirumalesh SRA, Kumari SS, Kumar KV, Roy $\mathrm{P}$, Balamurugan V (2019) Seroprevalence and distribution of serogroup-specific pathogenic Leptospira antibodies in cattle and buffaloes in the state of Andhra Pradesh, India, Veterinary World, 12(8): 1212-1217.

\begin{abstract}
Aim: In this study, the prevalence and the distribution status of Leptospira serogroup-specific antibodies among cattle and buffaloes in enzootic districts of Andhra Pradesh, a South Indian state was carried out.

Materials and Methods: A total of 426 serum samples were randomly sampled from various villages from Prakasam, Kurnool, Guntur, Chittoor, Srikakulam, Visakhapatnam, and Godavari districts of Andhra Pradesh between 2016 and 2017. Serum samples from cattle $(n=106)$ and buffaloes $(n=320)$ having a history of pyrexia, and reproductive problems such as agalactia, infertility, abortions, and stillbirth. The serum samples were screened for Leptospira-specific antibodies by microscopic agglutination test using a reference panel of 18 live cultures of pathogenic Leptospira serovars.
\end{abstract}

Results: The overall seropositivity of $68.08 \%$ (290/426) was observed with 70.8\% (75/106) in cattle and 67.18\% (215/320) in buffaloes. The frequency distribution of predominant serogroup-specific Leptospira antibodies in the sampled areas was determined against the employed serovars as follows: Icterohaemorrhagiae $-21.38 \%$, Hebdomadis $-18.97 \%$, Australis $-18.62 \%$, Pomona $-17.24 \%$, Sejroe - 15.86\%, Tarassovi - 15.86\%, Autumnalis - 15.52\%, Panama - 14.83\%, Shermani - 12.07\%, Javanica - 11.38\%, Hurstbridge - $11.03 \%$, and Pyrogenes $-10.69 \%$.

Conclusion: It was evident that bovines had a role in maintaining several predominant Leptospira serovars with the change in the trend over a period. The results from this study would also help in strategizing and mitigating the disease burden in cattle and buffaloes of the enzootic area.

Keywords: buffaloes, cattle, distribution of serovars, leptospirosis, microscopic agglutination test, seroprevalence.

\section{Introduction}

Leptospirosis is a global zoonosis caused by pathogenic strains of Leptospires [1]. The disease is neglected in most of the enzootic countries in the world due to lack of information and awareness of the extent of the public health problem [2]. The disease severity in humans and variety of mammalian hosts, such as rodents, cattle, buffaloes, sheep, goats, deer, pigs, dogs, camels, horses, raccoons, etc., impacts both public health and livestock economy [3]. The infection is usually transmitted by direct or indirect exposure to the skin (cuts/abrasions), mucous membranes (intact) to contaminated urine, placental fluids, etc. In cattle and other ruminants, leptospirosis accounts for great economic losses as a consequence of reduced milk yield (agalactia), abortion, stillbirth,

Copyright: Alamuri, et al. Open Access. This article is distributed under the terms of the Creative Commons Attribution 4.0 International License (http://creativecommons.org/licenses/ by/4.0/), which permits unrestricted use, distribution, and reproduction in any medium, provided you give appropriate credit to the original author(s) and the source, provide a link to the Creative Commons license, and indicate if changes were made. The Creative Commons Public Domain Dedication waiver (http:// creativecommons.org/publicdomain/zero/1.0/) applies to the data made available in this article, unless otherwise stated. reduced fertility, mortality in calves, decreased daily weight gain, the birth of weak calves, and mortality in calves $[3,4]$. Leptospira infection in bovines causes maintenance of bacteria in the host, leading to a carrier state. The incidence of cattle leptospirosis was first acknowledged in 1935 by Michin and Azinow. The Bernkopf isolated and established, Leptospira as the causative agent of disease in Palestine [5]. Since then, the disease is being reported globally, through infections by a wide variety of serovars, and with varied clinical outcomes [6].

Bovine leptospirosis has been sparsely reported in enzootic states of India. Seroprevalence of leptospirosis with various Leptospira serovars from farm animals in enzootic coastal states of India such as areas of Odisha, Maharashtra, Kerala, Tamil Nadu, Gujarat, and Andaman Islands [7-9] ranged from $14.55 \%$ [10] to $54.14 \%$ [11] has been reported. Further, a few studies have also been performed in urban areas, as leptospirosis has emerged as an important urban zoonosis [12]. The previous studies have reported seroprevalence of leptospirosis in Tamil Nadu [13], Kerala [14], Karnataka [15], and Andhra Pradesh [16]. However, the studies from Andhra Pradesh did not give the status on 
the breadth of circulating serovars as they were limited to only a few serovars $[11,16,17]$. Knowledge of prevalent Leptospira serovar(s) in a particular geographical area either in the incidental hosts or in carrier animals is essential to understand the epizootiology of the disease [18]; however, there are variations observed in the prevalence of serovars among different regions in a country or among different countries in the world. Moreover, it is often seen that bovine maintains several predominant Leptospira serovars with the change in the trend over a period.

Therefore, it is worthwhile to understand the prevalence and distribution of various serovars associated with leptospirosis over a period of time in specific geographical areas with the inclusion of more reference serovars in a test panel of microscopic agglutination test (MAT) including serovars of intermediate species [7]. This would help in understanding the linkage between circulating serovars in animals and humans as well as to apply strategies to mitigate the burden of leptospirosis. Since leptospirosis is a zoonosis, appropriate control measures can be adopted based on one health approach.

In this study, the prevalence and distribution of Leptospira serogroup-specific antibodies in cattle and buffaloes associated with a history of abortions and reproductive disorders, which are reared in rural areas (villages) of various districts, of Andhra Pradesh, India, were determined by employing a greater number of serovars in the antigen panel of MAT.

\section{Materials and Methods}

\section{Ethical approval and Informed consents}

Before sampling, the aim of the present study was explained to each farmer and the farmers who accepted to participate gave their oral consent before animal sampling. Moreover, samples were collected by well-trained veterinarians with respect regarding animal welfare regulations.

\section{Study area}

Andhra Pradesh takes a coastline of $974 \mathrm{~km}$ $(15.9129 \mathrm{~N}-79.7400 \mathrm{E})$ with the second extensive coastline among the states of India, after Gujarat. The study was conducted between 2016 and 2017 from different districts, namely, Chittoor, Guntur, Kurnool, Prakasam, Godavari, Srikakulam, and Visakhapatnam of Andhra Pradesh, where leptospirosis is enzootic.

\section{Serum samples}

A total of 426 random serum samples from cattle and buffaloes were collected by local Veterinarians from apparently healthy animals with a history of fever, and reproductive disorders such as reduced milk yield (agalactia), abortion, stillbirth, and infertility from different villages in selected areas in various districts as stated above. Collected serum samples were transported on ice and stored at $-20^{\circ} \mathrm{C}$ until further use.

\section{MAT}

All the serum samples were screened for Leptospira serogroup-specific antibodies by MAT as described earlier at 1:100 dilution $[19,20]$. A panel of 18 pathogenic reference serovars, namely, Australis, Bankinang, Canicola, Hardjo, Hebdomadis, Tarassovi, Pyrogenes, Icterohaemorrhagiae, Pomona, Shermani, Kaup, Grippotyphosa, Hurstbridge, Javanica, Panama, Djasiman, Copenhageni, and Bataviae was included in the antigen panel while employing MAT [19]. A MAT titer of $\geq 1: 100$ was taken as a positive reactor as per the $\mathrm{WHO} / \mathrm{OIE}$ manual for leptospirosis [20].

\section{Results and Discussion}

The Indian state of Andhra Pradesh has a rich inheritance of livestock rearing [21]. The prevalence data with specific serovars of Leptospira infection in the coastal and non-coastal regions are mostly unknown in enzootic states of India. The local abundance of several species of pathogenic serovars may be a useful indicator to assess the potential transmission among animals and to humans, and it may help in taking appropriate control measures [22].

Further, there are no ample reports on the magnitude of Leptospira exposure in the bovine population, especially some of the enzootic coastal states of India; however, this study was undertaken to determine the seroprevalence of leptospirosis among the bovine population in rural areas of different districts of Andhra Pradesh with the distribution of serogroup-specific antibodies. However, in the past decade, there have been a few studies on the prevalence of leptospirosis in Andhra Pradesh by MAT using a limited panel of serovars (Bankinang, Icterohaemorrhagiae, Canicola, Hardjo, Hebdomadis, Grippotyphosa, Javanica, and Pomona) [16] and Linnodee ELISA Hardjo kit [8].

The overall seropositivity of $68.07 \%(290 / 426)$ was observed from different studied areas of Andhra Pradesh with seropositivity of $70.75 \%$ $(75 / 106)$ in cattle and $67.18 \%(215 / 320)$ in buffaloes (Table-1), which was significantly higher than previously reported studies. This could be due to the samples collected from animals which were associated invariably with fever, abortion, and other reproductive problems and were suspected for leptospirosis. The results were in concordance with the earlier reported prevalence range from 45 to $70 \%$ while studying the bovine leptospirosis in enzootic states of India $[16,19]$. Balamurugan et al. [19] reported that seropositivity of $70.51 \%$ in cattle associated with reproductive problems in enzootic states of India, whereas Prameela et al. [16] observed the seropositivity of $44.73 \%$ with predominant serovar Pomona, Autumnalis, and Hardjo in cattle associated with pyrexia and abortions in the Andhra Pradesh, India.

Further on analysis, the highest seropositivity was observed in Visakhapatnam (71.43\%), followed by Chittoor (70.83\%), Guntur (70.45\%), Kurnool (69.86\%), Godavari (67.78\%), Srikakulam (65.79\%), and Prakasam (61.97\%) districts. According to the previous studies, high prevalence is often observed in the 


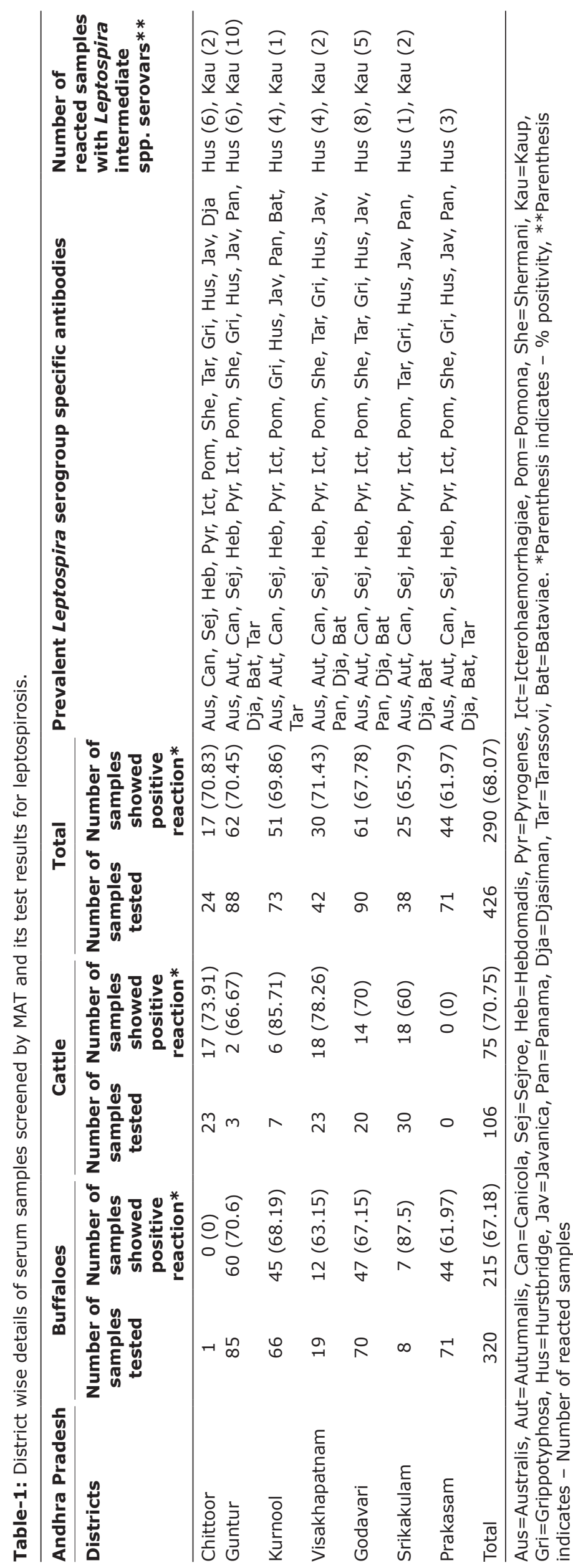


coastal regions compared to the non-coastal regions. Andhra Pradesh is a coastal state with most of its districts lying in the coastline such as Visakhapatnam, Srikakulam, and Prakasam. However, there was not much difference found in coastal and non-coastal districts, but the prevalence in the non-coastal districts (70.27\% [130/185]) was slightly higher compared to the coastal districts (66.39\% [160/241]) (Table-1). Whether it is a coastal or non-coastal region, the observed rearing conditions such as open herds, using shared bulls for breeding, and shared grazing with common water sources are almost similar in both the regions as there is a chance of getting the Leptospira infection by rearing conditions and management practices.

Table-2: Frequency percentage distribution of reacted pathogenic serovars in cattle and buffaloes in endemic districts of Andhra Pradesh.

\begin{tabular}{lcc}
\hline Leptospira serovars & $\begin{array}{c}\text { Overall } \\
\text { sample } \\
\text { reactivity }\end{array}$ & $\begin{array}{c}\text { Frequency } \\
\text { percentage } \\
\text { reactivity (\%) }\end{array}$ \\
\hline Hebdomadis & 55 & 18.97 \\
Australis & 54 & 18.62 \\
Pomona & 50 & 17.24 \\
Hardjo & 46 & 15.86 \\
Tarassovi & 46 & 15.86 \\
Bankinang & 45 & 15.52 \\
Panama & 43 & 14.83 \\
Icterohaemorrhagiae & 36 & 12.41 \\
Shermani & 35 & 12.07 \\
Javanica & 33 & 11.38 \\
Hurstbridge & 32 & 11.03 \\
Pyrogenes & 31 & 10.69 \\
Copenhageni & 30 & 10.34 \\
Bataviae & 29 & 10.00 \\
Kaup & 22 & 7.59 \\
Canicola & 21 & 7.24 \\
Djasiman & 20 & 6.90 \\
Grippotyphosa & 16 & 5.52 \\
\hline
\end{tabular}

The frequency distribution of pathogenic Leptospira antibodies was determined against various serovars employed as shown in Table-2. The major reacted prevalent pathogenic serovars (frequency distribution from 19 to $12 \%$ ) representing serogroup antibodies in different districts were Icterohaemorrhagiae, Hebdomadis, Australis, Pomona, Sejroe, Tarassovi, Autumnalis, Panama, Shermani, etc. Further, considering the serovars status, the predominant serovars pattern is similar to the studies conducted earlier by Balakrishnan et al. [11] and Prameela et al. [16] except that the serovars Australis and Hebdomadis observed in the present study along with other emerging pathogens of different serovars, as the change in trend of prevalent predominant serovars over a period of time noticed [23,24].

Although the serovar Hardjo is considered as common in cattle [25], other serovars are also prominent in many parts of the world. Moreover, the previous study conducted during 2008 in different districts of Andhra Pradesh showed 67.15\% $(92 / 137)$ in cattle and $61.9 \%(52 / 84)$ in buffaloes associated with reproductive problems with Pomona, Pyrogenes, Hebdomadis, Hardjo, Australis, etc., as predominant serovars [17]. Further, during the year 2011, Balakrishnan et al. [11] reported 50.21\% $(122 / 243)$ in cattle and $68.64 \%(90 / 118)$ in buffaloes with Hebdomadis, Pomona, Ballum, Hardjo, etc., as predominant serovars, whereas Prameela et al. [16] reported 44.73\% (17/38) prevalence with $35 \%$ Pomona, $17 \%$ Autumnalis, and $11.76 \%$ Hardjo as predominant serovars in cattle associated with pyrexia and abortions.

Further, the number of seropositive samples to intermediate and other Leptospira spp. serovars evidenced (Table-1), the re-emergence of Leptospira

Table-3: Cross-reactivity among different Leptospira serovars in cattle and buffaloes in endemic districts of Andhra Pradesh.

\begin{tabular}{|c|c|c|c|c|c|c|c|c|c|c|c|c|c|c|c|c|c|c|}
\hline Serovars & Aus & Ban & Can & Har & Heb & Pyr & Tar & Ict & Pom & She & Kau & Gri & Hus & Jav & Pan & Dja & Cop & Bat \\
\hline Aus & - & 14 & 3 & 2 & 12 & 3 & 11 & 5 & 10 & 2 & 3 & 1 & 8 & 1 & 4 & 1 & 1 & 3 \\
\hline Ban & - & - & 0 & 1 & 5 & 12 & 6 & 3 & 9 & 2 & 1 & 1 & 2 & 5 & 3 & 4 & 2 & 4 \\
\hline Can & - & - & - & 3 & 1 & 3 & 0 & 2 & 0 & 1 & 3 & 4 & 1 & 0 & 4 & 1 & 1 & 2 \\
\hline Har & - & - & - & - & 2 & 4 & 0 & 1 & 2 & 1 & 0 & 2 & 4 & 0 & 3 & 0 & 2 & 1 \\
\hline Heb & - & - & - & - & - & 4 & 19 & 6 & 15 & 6 & 5 & 3 & 7 & 10 & 8 & 1 & 8 & 4 \\
\hline Pyr & - & - & - & - & - & - & 1 & 0 & 6 & 1 & 1 & 2 & 5 & 4 & 2 & 3 & 2 & 2 \\
\hline Tar & - & - & - & - & - & - & - & 1 & 17 & 15 & 9 & 2 & 7 & 12 & 3 & 1 & 5 & 4 \\
\hline Ict & - & - & - & - & - & - & - & - & 4 & 2 & 2 & 4 & 2 & 3 & 7 & 5 & 4 & 6 \\
\hline Pom & - & - & - & - & - & - & - & - & - & 17 & 10 & 1 & 3 & 11 & 6 & 1 & 1 & 1 \\
\hline She & - & - & - & - & - & - & - & - & - & - & 9 & 1 & 6 & 11 & 5 & 2 & 3 & 1 \\
\hline Kau & - & - & - & - & - & - & - & - & - & - & - & 1 & 3 & 8 & 1 & 0 & 0 & 3 \\
\hline Gri & - & - & - & - & - & - & - & - & - & - & - & - & 3 & 1 & 3 & 0 & 3 & 2 \\
\hline Hus & - & - & - & - & - & - & - & - & - & - & - & - & - & 5 & 3 & 0 & 4 & 2 \\
\hline Jav & - & - & - & - & - & - & - & - & - & - & - & - & - & - & 7 & 2 & 4 & 1 \\
\hline Pan & - & - & - & - & - & - & - & - & - & - & - & - & - & - & - & 5 & 3 & 3 \\
\hline Dja & - & - & - & - & - & - & - & - & - & - & - & - & - & - & - & - & 2 & 0 \\
\hline Cop & - & - & - & - & - & - & - & - & - & - & - & - & - & - & - & - & - & 2 \\
\hline Bat & - & - & - & - & - & - & - & - & - & - & - & - & - & - & - & - & - & - \\
\hline
\end{tabular}

Aus=Australis, Ban=Bankinang, Can=Canicola, Har=Hardjo, Heb=Hebdomadis, Pyr=Pyrogenes,

Ict=Icterohaemorrhagiae, Pom=Pomona, She=Shermani, Kau=Kaup, Gri=Grippotyphosa, Hus=Hurstbridge, Jav=Javanica, Pan=Panama, Dja=Djasiman, Cop=Copenhageni, Bat=Bataviae, Tar=Tarassovi 
pathogens. Our earlier study indicates the prevalence of intermediate species serovars in ruminants in enzootic states of India [7], especially the emergence of Kaup and Hurstbridge serovars representing L. inadai and $L$. fainei species for bovine samples. Therefore, by employing 18 reference serovars panel in MAT, as against eight serovars employed in the earlier study [16], we could able to detect a greater number of seroreactive animals. The additional seropositivity of $15.02 \%$ (64/426) was observed while including other serovars in the test panels, which are not covered in the earlier study [16]. Further, a total of 10 bovine samples reacted (3.44\%) exclusively to Kaup (3) and Hurstbridge (7) with Leptospira intermediate spp. serovars.

The observed cross-reactivity between different serovars in cattle and buffaloes is presented in Table-3, with the major selected reacted reference serovars versus cross-reactive serovars are summarized in Table-4. Overall, with nine selected major reacted serovars (Hebdomadis, Australis, Pomona, Hardjo, Tarassovi, Autumnalis, Panama, Icterohaemorrhagiae, and Shermani) in the panel, it is possible to detect the Leptospira antibodies in bovine serum samples for providing diagnosis more than $82 \%$, in MAT with coverage ranges from 86 to $92 \%$ in some districts

Table-4: Majorly selected reacted serovars versus cross-reacted serovars.

\begin{tabular}{|c|c|}
\hline $\begin{array}{l}\text { Major selected } \\
\text { serovars }\end{array}$ & Cross-reacted serovars \\
\hline Hebdomadis & $\begin{array}{l}\text { Tar, Pom, Aus, Jav, Har, Pan, Cop, } \\
\text { Hus, Ict, She, Ban, Kau, Pyr, Bat, } \\
\text { Gri, Can, Dja }\end{array}$ \\
\hline Australis & $\begin{array}{l}\text { Heb, Ban, Tar, Hus, Pom, Har, Ict, } \\
\text { Pan, Can, Pyr, Kau, Bat, She, Gri, } \\
\text { Jav, Dja, Cop }\end{array}$ \\
\hline Pomona & $\begin{array}{l}\text { Tar, She, Heb, Har, Jav, Kau, Aus, } \\
\text { Ban, Pyr, Pan, Ict, Hus, Gri, Dja, } \\
\text { Cop, Bat, Can }\end{array}$ \\
\hline Hardjo & $\begin{array}{l}\text { Pom, Heb, Ban, Pyr, She, Jav, Aus, } \\
\text { Tar, Hus, Pan, Can, Cop, Gri, Ict, } \\
\text { Bat, Kau }\end{array}$ \\
\hline Tarassovi & $\begin{array}{l}\text { Heb, Pom, She, Jav, Aus, Kau, Hus, } \\
\text { Ban, Cop, Har, Bat, Pan, Gri, Pyr, Ict }\end{array}$ \\
\hline Bankinang & $\begin{array}{l}\text { Pyr, Aus, Har, Tar, Pom, Heb, Jav, } \\
\text { Dja, Bat, Pan, Ict, She, Hus, Cop, } \\
\text { Kau, Gri }\end{array}$ \\
\hline Panama & $\begin{array}{l}\text { Heb, Ict, Jav, Pom, She, Dja, Aus, } \\
\text { Can, Har, Ban, Tar, Gri, Hus, Cop, } \\
\text { Bat, Pyr }\end{array}$ \\
\hline Icterohaemorrhagiae & $\begin{array}{l}\text { Pan, Heb, Bat, Dja, Aus, Gri, Cop, } \\
\text { Pom, Jav, Ban, Can, She, Kau, Hus, } \\
\text { Har, Tar, Pyr }\end{array}$ \\
\hline Shermani & $\begin{array}{l}\text { Pom, Tar, Jav, Kau, Heb, Hus, Har, } \\
\text { Pan, Cop, Aus, Ban, Ict, Dja, Can, } \\
\text { Pyr, Gri, Bat }\end{array}$ \\
\hline $\begin{array}{l}\text { Total cross-reacted } \\
\text { serovars }\end{array}$ & $\begin{array}{l}\text { Heb, Tar, Pom, Aus, Jav, Har, Pan, } \\
\text { Cop, Hus, Ict, She, Ban, Kau, Pyr, } \\
\text { Bat, Gri, Can, Dja }\end{array}$ \\
\hline
\end{tabular}

Aus=Australis, Ban=Bankinang, Can=Canicola, Heb $=$ Hebdomadis, Pyr $=$ Pyrogenes, Tar=Tarassovi Ict=Icterohaemorrhagiae, Pom=Pomona, She=Shermani, Kau=Kaup, Gri=Grippotyphosa, Hus=Hurstbridge, Jav=Javanica, Pan=Panama, Dja=Djasiman, Cop=Copenhageni, Bat=Bataviae, Har=Hardjo
(Kurnool, Visakhapatnam, Prakasam, and Guntur) of Andhra Pradesh. Further, with the inclusion of two intermediate serovars, it is possible to cover overall $85 \%$ of the positive MAT reacted samples. However, in this study, as the samples were limited to a few villages in some districts, it is recommended that further testing be done using large sample size. In a nutshell, there was a significant change observed in the trend of prevalent predominant serovars in this particular geographical area over a period of time with the emergence of Hebdomadis, Australis, Panama, and Shermani including intermediate species serovars Kaup and Hurstbridge, etc.

\section{Conclusion}

The seroprevalence of leptospirosis among cattle and buffaloes in different districts of Andhra Pradesh was significantly high and bovine has a role in maintaining several predominant serovars with the change in trend over a period of time. The continuous presence of these Leptospires will lead to a potential zoonotic risk to slaughterhouse workers, meat inspectors, animal holders, agriculture laborers, farmers, etc., which also determines the need for continuous monitoring of leptospirosis in animals and in humans to combat this zoonosis. Although there have been studies conducted in different parts of India, it is difficult to assess the true nature of the disease in epizootiological point, due to inadequate sample size. Thus, intensive surveillance programs, preventive vaccinations, and control strategies to reduce the incidence or burden of bovine leptospirosis are warranted, which, in turn, help in reducing the zoonotic infections to various stakeholders including public health personnel.

\section{Authors' Contributions}

The present study is the part of AA's Ph.D., dissertation. AA visited the field, collected the samples and drafted the manuscript. AA, SRAT, and SSK carried out the laboratory experiment, KVK analyzed the data and edited the manuscript. PR provided guidance and support to carry out the experiments. VB designed the work with overall monitoring, analyzed the data and edited the manuscript. All authors drafted, read, and approved the final manuscript.

\section{Acknowledgments}

Authors wish to thank Indian Council of Agricultural Research Institute (ICAR), New Delhi, India, for encouragement and support. This part of the research work was funded from ICAR-Network project on Outreach Programme on Zoonotic Diseases (F.No. AS/14(1)/2009-ASR-IV). The authors also thank the ICAR-National Institute of Veterinary Epidemiology and Disease Informatics staff for constant support and timely help. We are grateful to the Andhra Pradesh State Animal Husbandry Department, and also the veterinarians and animal health assistants who helped in sample collection. 


\section{Competing Interests}

The authors declare that they have no competing interests.

\section{Publisher's Note}

Veterinary World remains neutral with regard to jurisdictional claims in published institutional affiliation.

\section{References}

1. Vijayachari, P., Sugunan, A. and Shriram, A. (2008) Leptospirosis: An emerging global public health problem. $J$. Biosci., 33(4): 557-569.

2. Srivastava, S.K. (2008) Current status of leptospirosis in India in animals and humans. Indian J. Vet. Pathol., 32(2): 179-186.

3. Ellis, W.A. (2015) Animal leptospirosis. Curr. Top. Microbiol. Immunol., 387: 99-137.

4. Thiermann, A.B. (1984) Leptospirosis: Current developments and trends. J. Am. Vet. Med. Assoc., 184(6): 722-725.

5. Smith, D.L.T. and Perry, D.A. (1952) Bovine leptospirosis case histories. Can. J. Comp. Med., 16(8): 294-294.

6. Faine, S., Adler, B., Bolin, C. and Perolat, P. (1999) Leptospira and Leptospirosis. Medisci Press, Melbourne.

7. Balamurugan, V., Thirumalesh, S.R.A., Sridevi, R., Govindaraj, G., Nagalingam, M., Hemadri, D., Gajendragad, M.R. and Rahman, H. (2016) Microscopic agglutination test analysis identifies prevalence of intermediate species serovars in ruminants in endemic states of India. Proc. Natl. Acad. Sci. India B Biol. Sci., 86(2): 469-475.

8. Balamurugan, V., Alamuri, A., Veena, S., Bharathkumar, K., Patil, S.S., Govindaraj, G. and Rahman, H. (2016) Investigation on the prevalence of Leptospira serovar Hardjo in organized cattle dairy farms of India. Indian J. Anim. Sci., 86(10): 1145-1147.

9. Sharma, S., Vijayachari, P., Sugunan, A.P. and Sehgal, S.C. (2003) Leptospiral carrier state and seroprevalence among animal population-a cross-sectional sample survey in Andaman and Nicobar Islands. Epidemiol. Infect., 131(2): 985-989.

10. Savalia, C.V. (2001) Seroprevalence of leptospirosis in bovines of Gujarat. Veterinar, 25(2): 4-5.

11. Balakrishnan, G., Roy, P., Govindarajan, R., Ramaswamy, V. and Manohar, M.B. (2011) Bovine leptospirosis in Andhra Pradesh. Indian Vet. J., 88(8): 140-141.

12. Hotez, P.J. (2017) Global urbanization and the neglected tropical diseases. PLoS Negl. Trop. Dis., 11(2): e5308.

13. Koteeswaran, A. (2006) Seroprevalence of leptospirosis in man and animals in Tamilnadu. Indian J. Med. Microbiol., 24(4): 329-331.

14. Adinarayanan, N. and James, P.C. (1980) Studies on leptospirosis in farm stock and wildlife in Kerala. Isolation of leptospires from divergent classes of animal hosts with an outbreak of cultural procedure. Indian Vet. J., 57(6): 495-500.

15. Upadhye, A.S. (1982) Leptospirosis an etiological agent of abortion in bovines. Indian J. Comp. Microbiol. Immunol. Infect. Dis., 3(4): 235-237.

16. Prameela, R.D., Sreenivasulu, D., Vijayachari, P. and Seenivasan, N.N. (2013) Seroepidemiology of leptospirosis in Andhra Pradesh. Arch. Clin. Microbiol., 4(2): 1-10.

17. Balakrishnan, G., Govindarajan, R., Meenambigai, T.V., Jayakumar, V. and Manohar, B.M. (2008) Seroprevalence of leptospirosis among domestic animals in Andhra Pradesh. Indian Vet. J., 85(5): 551-552.

18. Balamurugan, V., Veena, S., Thirumalesh, S.R.A., Alamuri, A., Sridevi, R., Sengupta, P.P., Govindaraj, G., Nagalingam, M., Hemadri, D., Gajendragad, M.R. and Rahman, H. (2017) Distribution of serogroup specific antibodies against leptospirosis in livestock in Odisha. Indian $J$. Anim. Sci., 87(5): 546-551.

19. Balamurugan, V., Alamuri, A., Bharathkumar, K., Patil, S.S., Govindaraj, G.N., Nagalingam, M., Krishnamoorthy, P., Rahman, H. and Shome, B.R. (2018) Prevalence of Leptospira serogroup-specific antibodies in cattle associated with reproductive problems in endemic states of India. Trop. Anim. Health Prod., 50(5): 1131-1138.

20. OIE. (2013) Office International des Épizooties (OIEWorld Organisation for Animal Health). Manual of Diagnostic Tests and Vaccines for Terrestrial Animals. OIE, France. p251-264.

21. Kishore, K. (2019) Livestock Rearing in the Indian Context LEISA. Available from: https://www.leisaindia.org/livestock-rearing-in-the-indian-context. Last accessed on 02-04-2019.

22. Chadsuthi, S., Bicout, D.J., Wiratsudakul, A., Suwancharoen, D., Petkanchanapong, W., Modchang, C., Triampo, W., Ratanakorn, P. and Chalvet-Monfray, K. (2017) Investigation on predominant Leptospira serovars and its distribution in humans and livestock in Thailand, 20102015. PLoS Negl. Trop. Dis., 11(2): e5228.

23. Lall, C., Kumar, K.V., Raj, R.V., Sugunan, A.P., Sunish, I.P., Sharma, S. and Vijayachari, P. (2017) Trend in the seroprevalence of Leptospirosis among cattle and goat populations of South Andaman. Indian J. Vet Res., 26(1): 37-40.

24. Raj, R.V., Kumar, K.V., Lall, C., Vedhagiri, K., Sugunan, A.P., Sunish, I.P., Sharma, S. and Vijayachari, P. (2018) Changing trend in the seroprevalence and risk factors of human leptospirosis in the South Andaman Island, India. Zoonoses Public Health, 65(6): 683-689.

25. Monte, L.G., Ridieri, K.F., Jorge, S., Oliveira, N.R., Hartwig, D.D., Amaral, M.G., Hartleben, C.P. and Dellagostin, O.A. (2015) Immunological and molecular characterization of Leptospira interrogans isolated from a bovine fetus. Comp. Immunol. Microbiol. Infect. Dis., $40: 41-45$. 